\title{
Roles of building simulation tools in sustainable building design
}

\author{
Zhiqiang (John) Zhai (ه), James S. McNeill \\ Department of Civil, Environmental and Architectural Engineering, University of Colorado at Boulder, UCB 428, ECOT 441, Boulder, CO 80309, USA
}

๑) Tsinghua University Press and Springer-Verlag Berlin Heidelberg 2013

The beginning of the modern sustainability movement in the United States began with the environmental movement of the 1960s. Books such as, Rachael Carson's Silent Spring, made the public more aware of the dangers they faced from industrial and agricultural toxins and pollutants. Several years later, in 1972, the United Nations held the Conference on the Human Environment in Stockholm, Sweden to discuss environmental concerns. Following this conference several national and international organizations such as, the United Nations Environmental Programme were formed. The work of those in the 1960s and 1970s environmental movement laid the groundwork for the concept of sustainability. In 1987, the United Nations World Commission on Environment and Development (WCED) report, Our Common Future created the definition of sustainable development that is most often used by the building industry. The WCED definition of sustainable development is, "development that meets the needs of the present without compromising the ability of future generations to meet their own needs (World Commission on Environment and Development 1987)." While this definition is somewhat vague and has many interpretations, it is notable for providing a concept that individuals can use to construct more descriptive definitions.

Sustainable building design is the application of sustainability to the built environment. Sustainable building design consists of methods to develop the built environment while meeting the intent of sustainable development. Broadly speaking, sustainable building design considers the economic, social and ecological impact of buildings on their surroundings. While this is an easy concept to understand, it requires a far different approach to building design than has traditionally been used by architects and engineers. One important and distinct aspect is that various simulation tools are booming in the last few decades that greatly assist the green building design and construction with quantitative data provided for decision support. Several prevalent modeling techniques are briefed below for their respective roles in green building design.

\section{Building energy modeling}

Building energy modeling can be applied early in the design phase, as a collaborative effort between the energy consultant and the architect. Initial energy modeling uses forward simulation models such as, the degree-day method, bin method, or hourly computer simulation tools to predict annual energy consumption and energy costs. The degreeday method is useful for a first order estimate, but the hourly computer simulation tools should be used for detailed analysis as they provide the most accurate results. The primary trade-off for the increased accuracy of hourly simulations is the increased time and effort that is required. Numerous hourly simulation programs are available, each with a different specialty.

As each tool has strengths and weaknesses, different simulation tools should be evaluated in order to determine the best choice for a particular application. This may necessitate the use of different simulation tools at various phases of a project. Some sort of energy simulation should be used during the early planning phase to determine the order of magnitude of impacts related to design alternatives. The type of early design impact analysis allowed by energy simulation tools is one of the key aspects of sustainable design.

\section{Computational fluid dynamics}

The use of computational fluid dynamics (CFD) for modeling the built environment has gained interest from both the research and professional worlds in the past several years, due to an increase in knowledge in the field, vastly increased computational power, and more accessible software. CFD

E-mail: John.Zhai@colorado.edu 
allows for the simultaneous solution and visualization of airflow, heat transfer, and contaminant transport. This tool is valuable for both researchers and designers of HVAC systems by aiding in the pre-construction evaluation of thermal comfort and indoor air quality. It also allows for designers to develop low-energy cooling and heating strategies such as natural ventilation systems and passive heating or cooling systems. The main disadvantages with CFD are that it requires an operator that is highly proficient in fluid dynamics and heat transfer and is very computationally intensive. An untrained user can easily produce results that are not representative of the actual physics. Simulations can take on the order of hours to days to complete with a standard workstation computer.

Researchers have been studying methods to link CFD with energy simulation programs (Zhai et al. 2002) in order to more accurately model air/envelope thermal interactions. Most simulation programs currently calculate the interior heat transfer under the assumption that the air within a room is well-mixed. This is not the case in many buildings, especially those using low-energy ventilation systems such as displacement ventilation. The wide application of coupled CFD and energy simulation still requires significant studies in fundamental algorithms, verifications and validations.

\section{Lighting modeling}

Simulation and rendering of illumination is critical to the effective design of advanced lighting systems. There are many programs that offer the solution of photometric calculations for the specification of luminaires by manufacturers. More sophisticated programs such as Radiance allow for accurate 3-dimensional modeling of interior spaces using ray tracing methods based on the calculation of luminance (Ward 1994). This allows lighting designers to determine accurate surface illuminaces with various light sources, even natural light. Lighting quality (visual comfort) can also be determined using these simulations, which is crucial to the proper design of daylighting systems. Similar to CFD, these lighting modeling programs allow energy efficient systems to be modeled and visualized during the design phase. This allows engineers and designers to work with owners to insure the program is being fulfilled, while minimizing energy use and maximizing comfort through an iterative design process.

The design of daylighting systems is a major focus of sustainable building design. It is estimated that 30\%-50\% of the energy consumption in typical office buildings is related to electrical lighting systems (Krarti 2000). Proper modeling of daylighting impacts can provide an estimate of the reduction in annual energy consumption by use of daylight harvesting systems.
Life cycle assessment

Current environmental life cycle assessment (LCA) considers not only the initial construction and operational phases, but aims to consider all processes that are required throughout the pre-construction, construction, operation, and deconstruction phases. This type of evaluation seeks to provide an accounting of the material and energy streams that enter and leave the building during its full life cycle. Life cycle analysis is quite common in industrial processes, but has yet to be commonly implemented in building design.

The LCA process is complex and data intensive. The advent of user friendly LCA tools is enabling building designers to use this assessment method much more easily. A number of tools are currently available, and some of these tools are fairly sophisticated and take into account energy and environmental impacts due to raw material extraction, production, construction, operation, demolition, and recycling. Detailed environmental analysis tools are a critical component in making design choices with minimal environmental impact.

\section{Building information modeling}

While building information modeling (BIM) is not a new concept, the building industry has recently focused more attention on the practical use of BIM tools. These tools replace the two-dimensional sketches of a building with a three-dimensional virtual prototype containing a database of component information. The primary determination of a BIM model is that all features are parametric objects. This allows objects to contain embedded information that relates components to each other. Practically speaking, a window is related to a wall. Therefore, by moving the wall the window moves as well. BIM allows the design team to integrate materials and specifications of the building into a database as the building is being designed, and to export input characteristics to other analysis tools, such as CFD or energy simulation. One of the most exciting parts of BIM is that it can streamline the design and construction process for all parties involved. Different team members share a common model that can be used for cost and energy analysis throughout the design. The model can also be passed on to the contractors and owners in order to improve communication of the design.

\section{Examples of the modeling techniques}

This issue presents ten great examples and case studies demonstrating some of the mentioned simulation techniques and their applications. One study integrates building energy modeling with life cycle cost (LCC) model to optimize the 
building envelopes of a commercial office building, while another study develops a simulation platform for assessing whole-year environmental comfort, energy consumption, and $\mathrm{CO}_{2}$ emissions in buildings and street blocks under dynamic microenvironments. CFD tools are employed to investigate the ventilation models and effectiveness in different built environments. Fundamental researches are also presented that target to develop more accurate and simple models for both indoor and outdoor airflow simulations. Applying appropriate engineering tools for new system design, evaluation and optimization is one of the main driving forces for producing new engineering modeling tools. This issue includes a few interesting system modeling applications that range from pipe drag reduction study, to solar-powered water adsorption chiller development, and to industrial waste heat based ground heat exchanger system optimization for district heating.

Eight of these ten papers are hand-picked and invited from the pool of recommended 50 top papers, according to the quality and relevance to the journal, from the Second International Conference on Building Energy and Environment (COBEE) held in Boulder, Colorado in August, 2012. All these papers have gone through a rigorous and standard review process of the journal and demonstrate important progresses in respective fields.

\section{References}

Krarti M (2000). Energy Audit of Building Systems: An Engineering Approach. New York: CRC Press.

Ward GJ (1994). The RADIANCE lighting simulation and rendering system. In: Proceedings of SIGGRAPH Conference, Orlando, USA, 1994.

World Commission on Environment and Development (1987). Our Common Future. New York: Oxford University Press.

Zhai Z, Chen Q, Haves P, Klems JH (2002). On approaches to couple energy simulation and computational fluid dynamics programs. Building and Environment, 37: 857-864. 